\title{
Editorial
}

\section{Chico Pereira, Ganador del Premio Cinematográfico de la Agencia Europea para la Seguridad y la Salud en el Trabajo con el largometraje "El Invierno de Pablo"}

\section{The Film "Pablo's Winter" of Chico Pereira, Winner of the film award fron the European Agency for Safety and Health at Work}

\author{
Maria Dolores Limón Tamés \\ Directora del Instituto Nacional de Seguridad y Salud en el Trabajo. Madrid. España. \\ Recibido: 12-12-12 \\ Aceptado: 12-12-12

\section{Correspondencia} \\ María Dolores Limón Tamés \\ Instituto Nacional de Seguridad e Higiene en el Trabajo (INSHT) \\ Torrelaguna, 73 \\ 28027 - Madrid. España. \\ Tfno: $913634120 / 21$ \\ Fax: 913634328 \\ Correo electrónico: direccioninsht@insht.meyss.es
}

Resumen

La Agencia Europea para la Seguridad y la Salud en el Trabajo (EU-OSHA) organiza cada año el Festival de Cine Documental de Leipzig (DOK, Leipzig) en el que se otorga el Premio Cinematográfico "Lugares de Trabajo Saludables" al documental que destaque como promotor del debate y la reflexión entre los ciudadanos europeos sobre la importancia de la seguridad y la salud en el trabajo. Este año 2012, el Premio ha sido otorgado al largometraje "El invierno de Pablo" del director español Chico Pereira, que narra la cruda historia de Pablo, un minero jubilado que trabajó extrayendo cinabrio durante 30 años y que actualmente presenta unos pulmones y un corazón seriamente dañados como consecuencia de la continua exposición al sulfuro de mercurio.

En España, la Red Española de Seguridad y Salud en el Trabajo, coordinada por el Instituto Nacional de Seguridad e Higiene en el Trabajo, organizará durante 2013 sesiones de cine forum en la que se podrán visionar las películas ganadoras del Certamen Cinematográfico "Lugares de Trabajo Saludables", como actividad divulgativa para el debate y la promoción de la cultura preventiva.

Med Segur Trab (Internet) 2012; 58 (229) 291-293

Palabras clave: Agencia Europea, EU-OSHA, Salud, Trabajo, Ocupacional, DOK, Leipzig, Red Española SST, INSHT, Prevención. 


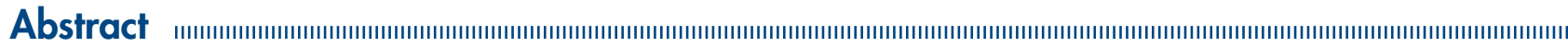

The European Agency for Safety and Health at Work (EU-OSHA) is supporting every year the Healthy Workplaces Film Award for the best documentary on work-related topics. The award is presented at the International Leipzig Festival for Documentary and Animated Film (DOK Leipzig).

The award honours a documentary film that promotes the importance of workplace health and safety across Europe. The film "Pablo's Winter" won this year the edition, telling the story of a retired miner who had been working during 30 years in an old mercury mine in Spain and currently has his heart and lungs severely damaged as a result of continued exposure to mercury sulfide.

In Spain, the Spanish Network of Safety and Health at Work, coordinated by the National Institute of Safety and Health at Work, is organizing during 2013 video screenings of documentary films awarded, as an activity for promoting health and safety at work to encourage preventive culture.Key Words: Human Rights, Copyright, authorship, Open Access, Creative Commons.

Med Segur Trab (Internet) 2012; 58 (229) 291-293

Key words: European Agency, EU-OSHA, Health, Work, Occupational, DOK, Leipzig, Spanish Network SST, INSHT, Prevention. 
La Agencia Europea para la Seguridad y la Salud en el Trabajo (EU-OSHA) celebró el pasado mes de octubre de 2012 en Edimburgo (Escocia), el Festival de Cine Documental de Leipzig (DOK, Leipzig) en el que se otorga el Premio Cinematográfico "Lugares de Trabajo Saludables". Este certamen cinematográfico tiene como objetivo destacar la importancia de las condiciones laborales de las personas en un mundo en constante cambio a través de las distintas películas documentales seleccionadas.

Las películas candidatas a este certamen cinematográfico deben mostrar entornos de trabajo o situaciones laborales que guarden relación con las condiciones de seguridad y salud de los trabajadores. El Premio cinematográfico "Lugares de Trabajo Saludables" se otorga a la película documental de autor, seleccionada entre las candidatas por su papel como promotor del debate y la reflexión entre los ciudadanos europeos sobre la importancia de la seguridad y de la salud en el trabajo. En la selección de candidaturas, además, se valoran otros aspectos como la calidad narrativa, la calidad de interpretación de sus personajes, así como los trabajos de cámara, sonido y montaje.

Este año fueron seleccionados ocho trabajos cinematográficos presentados por diferentes países europeos, recayendo finalmente el Premio en el largometraje "El invierno de Pablo" de Arturo Delgado Pereira (Chico Pereira), realizador y guionista de 34 años de edad, natural de Almadén (Ciudad Real), que realizó sus estudios en la Escuela de Artes Visuales Ryerson University de Toronto (Canadá) y posteriormente en la Napier University de Edimburgo (Escocia), ciudad en la que reside actualmente desde hace algunos años.

El reciente Premio obtenido por Chico Pereira en el Festival de Edimburgo no es el primero que alcanza a lo largo de su corta carrera profesional, pues este joven director cinematográfico ha obtenido varios premios en diferentes festivales tanto nacionales (Madrid y Barcelona) como internacionales (Edimburgo, Italia, Puerto Rico y Reino Unido con el Premio BAFTA para jóvenes talentos de la British Academy of Film and Television Arts).

La película "El invierno de Pablo", galardonada con un premio de 8.000 euros y la producción de 1.000 copias en las 24 lenguas de la UE, se desarrolla en el pueblo de Almadén. La obra tiene lugar en un escenario cuyo telón de fondo son las minas de mercurio y cuyo argumento realiza una disección social, laboral y humana a través de la cruda historia de Pablo, un minero jubilado que se pasó extrayendo cinabrio durante 30 años y que actualmente presenta unos pulmones y un corazón seriamente dañados como consecuencia de la continua exposición al sulfuro de mercurio.

Con esta obra cinematográfica, Chico Pereira, además de describir la realidad de un pueblo entregado a la mina, rinde homenaje a sus gentes y a su pueblo natal, cuyas minas, junto a las de Idrija en Eslovenia, han sido incluidas el pasado 30 de junio en la lista de Patrimonio Mundial de la UNESCO, después de un largo proceso que tuvo inicio en 2006.

Es destacable la labor de sensibilización que se realiza a través de las películas documentales seleccionadas en el certamen cinematográfico "Lugares de Trabajo Saludables", llevando al público el verdadero desenlace de situaciones laborables concretas o el drama que puede sobrevenir como consecuencia de deficientes condiciones de seguridad y salud en el trabajo. Con dicho objetivo, la Agencia Europea organiza cada año este Festival, que en cada edición está logrando mayor repercusión en el ámbito cinematográfico de películas documentales, consiguiendo así acercar al público el sentir de la necesidad de garantizar lugares de trabajo seguros y saludables.

La Agencia Europea, en colaboración con su Red de Centros de Referencia, promoverá la proyección de las películas documentales en todos los Estados miembros de la Unión Europea.

En España, la Red Española de Seguridad y Salud en el Trabajo, coordinada por el Instituto Nacional de Seguridad e Higiene en el Trabajo, organizará durante 2013 sesiones de cine forum en la que se podrán visionar las películas ganadoras del Certamen Cinematográfico "Lugares de Trabajo Saludables". Dicha información estará disponible en la página web de la Red y del INSHT (https://osha.europa.eu/fop/spain/ es/index.stm, http://www.insht.es). 